Tatar, B., Kıymık, H. / Journal of Yasar University, 2021, 16/64, 1700-1719

\title{
Finansal Tablolarda Hile Riskinin Tespit Edilmesinde Veri Madenciliği Yöntemlerinin Kullanılmasına Yönelik Bir Araştırma ${ }^{1}$ \\ A Study on the Use of Data Mining Methods to Detect Financial Statement Fraud Risk
}

\author{
Büşra TATAR, Mehmet Akif Ersoy Üniversitesi, busratatarr07@gmail.com \\ Orcid No: 0000-0002-5404-2658 \\ Hakkı KIYMIK, Mehmet Akif Ersoy Üniversitesi, hkiymik@mehmetakif.edu.tr \\ Orcid No: 0000-0002-4121-8060
}

\begin{abstract}
Öz: Çalışmanın amacı, 2015-2019 yılları arasında hisse senetleri BISTT Tekstil, Giyim Eşyası ve Deri sektöründe işlem gören şirketlerin bă̆ımsız denetimden geçmiş finansal tablolarına yönelik hile riskinin veri madenciliğine dayall yöntemler kullanılarak finansal oranlar aracılığıla tespit edilmesi ve buna bağll olarak bu yöntemlerin hileyi tespit etme başarısının ortaya çıkarılmasıdır. Bu amaçla bağımsız denetim raporları ve haftalık SPK Bültenleri çalışma kapsamında incelenerek hileli finansal raporlama uygulamalarına başvurma durumları tespit edilmiştir. Bu kapsamda ilgili dönemlere ait 127 finansal tablo ve bağımsı denetim raporu incelenmiştir. Çalışmada, literatürde hileli finansal raporlamayı açıklamada kullanılan 12 finansal oran ile veri madenciliğine dayalı 10 yöntem kullanılmıştır. Araştırma bulgularına göre, çalışma kapsamında kullanılan veri madenciliğine dayalı tüm modellerin, hile riski taşıdığı kabul edilen finansal tablolar ile hile riski taşımadı̆̆ kabul edilen finansal tabloları doğru sınıflandırmada \%70'in üzerinde başarll olduklarl ve en başarll yöntemlerin J48 ve Derin Ö̆̆renme yöntemleri ile kurulan modeller olduğu sonucuna ulaşılmıştır.
\end{abstract}

Anahtar Sözcükler: Hileli Finansal Raporlama, Finansal Oranlar, Hile Riski, Veri Madenciliği

JEL Siniflandirmasi: M40, M42, G39

Abstract: The aim of this study is to determine the fraud risk of the independently audited financial statements of companies whose stocks are traded in the Borsa Istanbul Textile, Clothing and Leather sector between 2015-2019 using data mining-based methods, through financial ratios, and accordingly, to reveal the success of these methods in detecting fraud. For this purpose, independent audit reports and weekly Capital Market Boards of Turkey $(C M B)$ Bulletins were examined within the scope of the study, and cases of applying to fraudulent financial reporting practices were determined. In this context, 127 financial statements and independent audit reports of relevant periods were examined. In the study, 12 financial ratios used in literature to explain fraudulent financial reporting and 10 methods based on data mining were used. According to research findings, all models based on data mining used within the scope of the study were more than $70 \%$ successful in correctly classifying financial statements that are considered to have fraud risk and financial statements that are considered to have no fraud risk, and the most successful methods are models established with J48 and Deep Learning methods.

Keywords: Fraudulent Financial Reporting, Financial Ratios, Fraud Risk, Data Mining

JEL Classification: M40, M42, G39

\section{Giriş}

Ulusal ve uluslararası literatür incelendiğinde, muhasebe usulsüzlükleri ile ilgili birçok kavramın kullanıldığı ve bu kavramların zaman zaman birbirlerinin yerine de kullanılabildiği görülmektedir. Muhasebe usulsüzlükleriyle ilgili genel olarak yaratıcı muhasebe ve hileli finansal raporlama olmak üzere iki kavramla karşılaşılmaktadır. Bu iki kavramın ortak noktası, finansal tablo kullanıcılarının bilerek ve isteyerek yanıltılmasıyla sonuçlanmasıdır. Bu iki

\footnotetext{
${ }^{1}$ Bu çalışma, "Finansal Tablo Hilelerinin Tespit Edilmesinde Veri Madenciliği Yöntemlerinin Kullanılmasına Yönelik Bir Araştırma' ' başlıklı yüksek lisans tezinin gözden geçirilmiş ve revize edilmiş halidir.
} 
kavramı birbirinden ayıran nokta ise finansal tablo kullanıcılarının yanıltılmasına sebep olan muhasebe uygulamasının yapılış şeklidir. İşletmeler veya yöneticileri tarafından muhasebe uygulamalarında genel kabul görmüş muhasebe ilkeleri ve standartlarına aykırı olmayan uygulamalar yapılmak suretiyle bu eylemin gerçekleştirilmesi halinde yaratıcı muhasebeden bahsetmek mümkündür. Ancak gerçekleştirilen işlemin genel kabul görmüş muhasebe ilkelerine ve muhasebe standartlarına aykırı olması durumunda ise hileli finansal raporlama söz konusu olmaktadır. Şirket yöneticileri, kendilerine emanet edilmiş olan işletme kaynaklarını iyi ve verimli bir şekilde kullandıklarını göstermek, yüksek primler elde etmek veya şirket lehine avantaj sağlamak gibi farklı bir takım amaçları gerçekleştirebilmek için bu yönteme başvurabilmektedirler.

Finansal tabloların güvenilirliği sadece yatırımcının korunması için değil aynı zamanda sermeye piyasalarının gelişimi açısından da önem arz etmektedir. Nitekim geçmiş yıllarda yaşanan Enron, WorldCom, Global Crossing gibi şirketlerin çöküşleri kurumsal yönetimin etkinliği, finansal raporların kalitesi ve denetim fonksiyonlarının güvenilirliği konusunda kötü bir izlenim bırakmasına neden olmuştur. Sermaye piyasası katılımcıları, kurumsal yönetimin ihtiyatlı ve aktif olmasını ve ortaya çıkan finansal bilgilerin doğru, kaliteli, şeffaf olmasını beklemektedirler. Ancak hileli finansal raporlama uygulamaları, piyasa katılımcılarının denetimden geçmiş olsalar dahi finansal tablolara olan güvenini olumsuz yönde etkilemektedir (Rezaee, 2005: 288).

Hileli finansal raporlama eyleminin, finansal tablo kullanıcısı olsun ya da olmasın birçok kesimi etkiliyor olmasından dolayı tüm dünyada bu tip işlemlerin önlenebilmesi için yasal düzenlemeler yapılmaktadır. Literatürde, finansal tablo hilelerinin tespit edilmesinde kullanılan yöntemler, kalitatif/kantitatif ve proaktif/reaktif yöntemler olmak üzere farklı şekillerde sinıflandırılmaktadır. Hileli finansal raporlamanın tespitinde kullanılan yöntemlerden biri de veri madenciliğine dayalı yöntemlerin kullanımıdır. Veri madenciliği yöntemlerinde, sonuçları önceden bilinen verilerden hareket edilerek geliştirilen bir model aracılığıyla sonuçları bilinmeyen veri setlerinin sonuç değerlerinin tahmin edilmesi amaçlanmaktadır.

Tüm bu açıklamalar doğrultusunda, bu çalışmanın amacı hile riski taşıdığı tespit edilen finansal tabloların içerdiği hile riskinin tespitinde, literatürde sıklıkla kullanılan finansal oranlar kullanılarak, veri madenciliğine dayalı yöntemlerin başarısını test etmektir. Çalışmanın amacına uygun olarak, araştırmanın problemi hile riski taşıyan finansal tabloların veri madenciliğine dayalı yöntemler aracılığıyla tespit edilmesidir. Çalışmada öncelikle konuyla ilgili ulusal ve uluslararası literatür taraması verilmiş, sonrasında hileli finansal raporlama ve 
tespitine ilişkin kavramsal çerçeve ortaya konmuş ve son olarak araştırma bulguları açıklanmıştır.

\section{Literatür Taraması}

Hileli finansal raporlamanın (HFR) tespitiyle ilgili ulusal ve uluslararası literatürde yapılmış birçok çalışma bulunmaktadır. Bu çalışmaların bir kısmında geleneksel tespit yöntemleri kullanılmış bir kısmında ise bu çalışmanın da konusunu oluşturan veri madenciliğine dayalı yöntemler kullanılmıştır. HFR'nin veri madenciliğine dayalı yöntemler aracılığıyla tespitine yönelik yapılmış olan çalışmalar aşağıda özetlenmiştir.

Spathis (2002), lojistik regresyon analizi yöntemini kullandığı çalışmasında belirlenen bazı finansal oranların finansal tablo hilelerinin tahmininde kullanılmasının anlamlı sonuçlar ortaya çıkardığını tespit etmiştir. Araştırmacı, çalışmasında finansal tablo hilelerinin açıklanmasında anlamlı gördüğü finansal oranları Net Kâr/Varlıklar, Brüt Kâr/Varlıklar, Çalışma Sermayesi/Varlıklar ve Yabancı Kaynaklar/Varlıklar olarak tespit etmiştir.

Koskivaara (2004) çalışmasında, yapay sinir ağına (YSA) dayalı destek sistemlerinin denetim alanlarında kullanılabileceği fikrini ortaya koymuştur. Araştırmacı çalışmasında, YSA uygulamalarının denetim amacına bağlı yapılan çalışmaların literatür taramasını yapmış ve YSA'nın genel olarak olası hatalar ile yönetim hilelerinin tespit edilmesinde kullanılabileceğini kanıtlamıştır.

Kotsiantis, Koumanakos, Tzelepis ve Tampakas (2006) yaptıkları çalışmalarında, 20012002 yılları arasında Yunanistan'da faaliyet gösteren 164 firmanın (hileye karışmış ve karışmamış) verilerini kullanarak makine öğrenme tekniklerinden karar ağacı, C4.5 algoritması, varyant metodolojisi kullanan algoritmalar ve Bayes ağları ile hileli finansal tabloları tespit etmeye çalışmışlardır. Araştırma sonucunda finansal tablo hilelerinin tahmin edilmesinde kullanılan karar ağacı modelinin diğer veri madenciliği yöntemlerinden daha başarılı olduğu sonucuna ulaşmışlardır.

Liou (2008) tarafından yapılan çalışmada, lojistik regresyon, karar ağacı ve yapay sinir ağları modellerini kullanılarak finansal tablo hilelerinin tahmin edilmesi amaçlanmıştır. Çalışmanın sonucuna göre karar ağacı yönteminin hile yapan firmaları \%100, hile yapmayan firmaları ise \%91 oranında doğru tahmin ettiği sonucuna ulaşılmıştır.

Ata ve Seyrek (2009) tarafından yapılan çalışmada hisse senetleri İMKB'de işlem gören 100 firmanın finansal tablo hilelerine başvuran ve başvurmayan şirket ayrımını karar ağacı yöntemi kullanarak 50 hile yapan ve 50 hile yapmayan firma olarak tanımlanmıştır. Çalışmada 24 farklı rasyo kullanılarak analiz gerçekleştirilmiştir. Çalışma sonucunda finansal tablo 
hilelerini tespit etmede "kaldıraç oranı" ile "aktif kârlılık oranının" önemli finansal oranlar olduğu belirlenmiştir. Ayrıca finansal tablo hilelerinin tespit edilmesinde YSA modelinin karar ağacı modeline göre daha başarılı olduğu sonucuna ulaşılmıştır.

Terzi (2012) karar ağacı, yapay sinir ağları ve genetik algoritma modellerini kullandığı çalışmasında, finansal tablo hilelerinin tahmin edilmesindeki başarı oranlarını karşılaştırmıştır. Araştırmacı bu amaçla değişken olarak çok sayıda finansal oran belirlemiştir. Analiz sonuçlarına göre karar ağacı modelinin diğer modellere kıyasla en yüksek doğru sınıflandırma başarısına sahip olduğu sonucuna ulaşmıştır.

Kırlığlu ve Ceylan (2014) çalışmalarında BIST Ulusal Pazar ve Gözaltı Pazarında hisse senetleri işlem gören şirketlerin 2013 yılına ilişkin finansal tablolarını incelemişlerdir. Çalışmada veri madenciliği yöntemlerinden Naive Bayes ve K-En Yakın Komşu Algoritmaları kullanılmıştır. Araştırma sonucunda K-En Yakın Komşu Algoritması kullanılarak oluşturulan modelin \%95 başarı düzeyinde doğru sınıflandırma yaptığı sonucuna ulaşılmıştır.

Liu, Chan, Kazmi ve Fu (2015) çalışmalarında finansal tablo hilelerinin tespiti ve sekiz farklı değişken kombinasyonunun doğruluğunu tespit etmeyi amaçlamışlardır. Çalışmada, Çin borsasında 1998-2014 yılları arasında listelenen şirketlerden 138'i hile yapan ve 160'1 hileye karışmayan şirket olarak sınıflandırılmıştır. Araştırmada, Rastgele Orman, Lojistik Regresyon, K-Ortalama, Karar Ağacı ve SVM modelleri kullanılmıştır. Araştırma sonucunda, \%88 doğruluk oranı ile Rastgele Orman modelinin diğer modellerden daha yüksek doğruluğa sahip olduğu sonucuna ulaşılmıştır.

Dutta, Dutta ve Raahemi (2017) çalışmalarında, 2001-2014 yılları arasında 3.513 yeniden düzenleme vakası içeren kapsamlı bir gerçek veri kümesi kullanarak hem hileli hem de hatalı finansal tahmine dayalı modeller geliştirmeyi amaçlamışlardır. Araştırmada, Karar Ağacı, Yapay Sinir Ağı, Naive Bayes, SVM ve Bayesian İnanç Ağlarını kullanılarak modeller oluşturulmuştur. Araştırma sonucunda Yapay Sinir Ağı algoritmasının diğer veri madenciliği yöntemlerinden daha iyi performans gösterdiği tespit edilmiştir.

Kopun (2018) tarafından yapılan çalışmada veri madenciliği yöntemlerinin uygulanmasına ilişkin bazı araştırmaların finansal tablo hilelerini tespit etmeye yönelik hangi finansal oranları kullandığ 1 incelenmiştir. Çalışma kapsamına giren araştırmalarda finansal tablo hilesinin tespitinde kullanılan 110 farklı finansal ve finansal olmayan oranın kullanıldığ sonucuna varılmıştır. Araştırmada finansal tablo hilelerinin açıklanmasında en sık kullanılan finansal oranları şu şekilde sıralamaktadır; envanter satış oranı, satışların toplam varlıklara oranı, alacaklar/satış oranı, işletme sermayesinin toplam aktiflere oranı, toplam borç/toplam varlık oranı, vergilendirmeden sonraki kâr/toplam varlıklar ve net kâr marjı oranıdır. 
Ye, Xiang ve Gan (2019) çalışmalarında finansal tablo hilelerinin tespit edilmesinde çeşitli sınıflandırma modellerinin karşılaştırmasını yapmışlardır. Araştırmacılar çalışmasında, 20072017 yılları arasında Çin'de halka açık olan 11.726 verinin hileli finansal raporlama tespiti için mali tablo incelemesini yapmışlardır. Çalışmada veri madenciliği yöntemlerinden Yapay Sinir Ağı, Lojistik Regresyon, SVM, CART, Karar Ağaçları, Bayes Ağları ve AdaBoost modellerini kullanılmıştır. Çalışma sonucunda Rastgele Orman yönteminin diğer algoritmalardan daha iyi performans gösterdiği tespit edilmiştir.

Craja, Kim ve Lessmann (2020) tarafindan yapılan çalışmada 1999-2019 yılları arasında ABD şirketlerinin yıllık mali raporlarından elde edilen veriler kullanılarak, finansal tablo hilelerinin tespitinde veri madenciliğine dayalı yöntemlerin gücü test edilmiştir. Araştırmada, Lojistik Regresyon, SVM, Random Forest, Extreme Gradient Boosting ve Yapay Sinir Ağ1 modelleri kullanılmıştır. Araştırma sonucunda, kullanılan tüm veri madenciliği yöntemlerinin doğruluk oranlarının yüksek olduğu sonucuna ulaşılmıştır.

\section{Hileli Finansal Raporlama}

İşletmelere ait finansal tablolar, işletmenin gerçek durumunu yansıttığı ölçüde anlamlıdır. Gerçekleştirilen çeşitli muhasebe usulsüzlükleri sonucu ortaya çıkan ve gerçekçi olmayan finansal tablolar, başta yatırımcılar, işletme sahip ve çalışanları olmak üzere devlet, kredi verenler ve işletme ile ticari ilişkide olan tüm kesimlerin zarara uğramasına sebep olabilmektedir (Altıntaş, 2010: 151). Tüm finansal tablo kullanıcıları için gerçeğe uygun makul bir güvence vermeyen finansal bilginin sunulması ise hileli finansal raporlama (HFR) anlamına gelmektedir (Çıtak, 2009: 86).

Muhasebenin bilgi sunma fonksiyonu, finansal tablolar aracılığıyla yerine getirilmektedir. HFR, finansal tablo kullanıcılarının yanıltılması amaciyla finansal tablolarda olması gereken tutar veya açıklamaların hiç kaydedilmemesi ya da yanlış kaydedilmesiyle finansal tabloların yanıltıcı şekilde düzenlenmesidir (Özbirecikli, 2013: 217).

AICPA tarafindan yayımlanan SAS No: 99 denetim standardında HFR, "finansal tablo kullanıcılarını aldatmak amacıyla kasıtlı bir şekilde finansal tablolarda yer alması gereken tutarların yer almaması veya olmaması gereken tutarların finansal tablolarda yer alması" şeklinde ifade edilmektedir. Ayrıca, finansal tablo kullanıcıları iki şekilde yanıltılmaktadır. Bunlar; HFR' den kaynaklanan yanlışlıklar ve varlıkların kötüye kullanılmasından kaynaklanan yanlışlıklardır (AICPA, SAS No.99, md.6).

SPK tarafından yayımlanmış olan tebliğe göre HFR, "Kasıtlı olarak, finansal tablolarda olması gereken tutarların ya da açıklamaların yer almaması veya yanlış beyan edilmesi sureti 
ile finansal tablo kullanıcılarının yanıltılmasıdır" șeklinde tanımlanmaktadır. Tebliğe göre mali tabloların hazırlanmasına dayanak teşkil edilen muhasebe kayıtları ve tevsik edici belgeler üzerinde yapılan usulsüzlükler ile muhasebe ilkelerinin kasıtlı olarak yanlış uygulanması HFR'ye sebep olan uygulamalar olarak belirtilmektedir (SPK, Seri X, No.22 Tebliğ, 6).

\subsection{Hileli Finansal Raporlama Yöntemleri}

İşletmeler ve/veya yöneticileri farklı amaçlarla hileye başvurabilmektedirler. Küçük işletmeler, vergisel kaygılarla genel olarak varlıklarını ve kârlarını olduğundan düşük göstermek amacıyla hileye başvurabilmektedirler. Büyük işletmeler ise ihtiyaç duydukları fona farklı kaynaklardan daha kolay ulaşabilmek için varlıklarını ve kârlarını olduğundan fazla göstermeyi isteyebilmektedirler (Can, 2010: 28-29). Farklı amaçlarla başvurulan hileli finansal raporlama, farklı yöntemler kullanılarak gerçekleştirilebilmektedir. Hile yöntemleri ile ilgili araştırmacılar tarafından farklı birçok hile sınıflandırmaları yapılmıştır. Literatür incelendiğinde hile ile ilgili çalışmalarda genel olarak ACFE tarafından yapılmış olan hile sınıflandırmasının kullanıldığı görülmektedir. ACFE tarafından yapılan hile sınıflandırmasının hileli finansal raporlama ile ilgili kısmı Şekil 1'de gösterilmiştir.

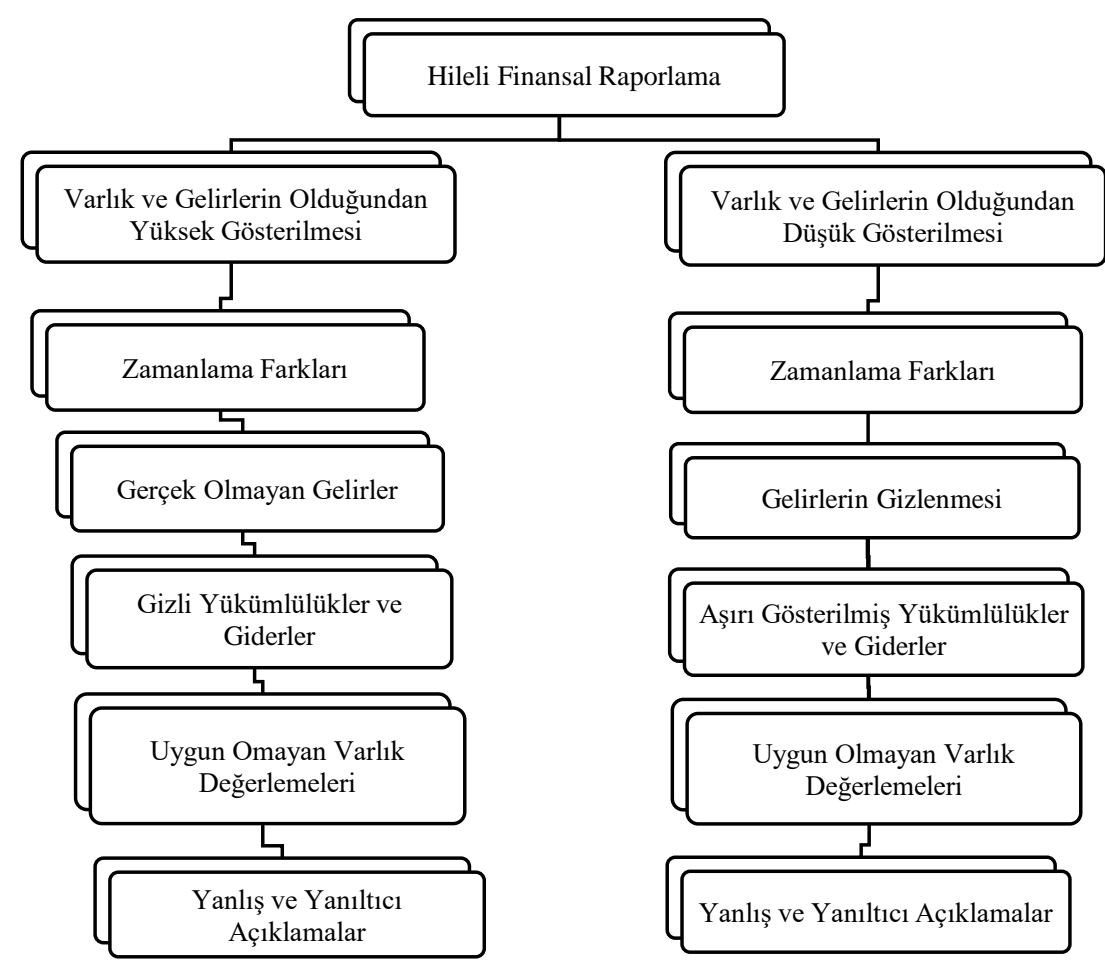

Şekil 1. Hileli Finansal Raporlama Yöntemleri

Kaynak: ACFE, 2020.

ACFE tarafından yapılan sinıflandırmaya göre hileli finansal raporlama yöntemleri, işletmenin durumunu olduğundan iyi göstermek veya kötü göstermek amacıyla yapılan işlemler 
olarak sınıflandırılmıştır. Gelirlerin olduğundan fazla gösterilmesine yönelik hileler genellikle, hayali gelir kaydı yapılması, gelirin erken veya geç tanınması veya giderlerin gizlenmesi yoluyla yapılabilmektedir. Varlıkların olduğundan fazla gösterilmesine yönelik hileler ise genellikle uygun olmayan varlık değerleme yöntemlerinin kullanılması yoluyla yapılmaktadır. Varlık ve gelirlerin olduğundan düşük gösterilmesi ise teoriye göre imkân ve ihtimal dâhilinde gerçekleşen fakat uygulamada pek karşılaşılmayan hile yöntemleridir. $\mathrm{Bu}$ hile yöntemi genellikle küçük işletmelerde görülmektedir (Demir vd., 2019: 119).

\subsection{Hileli Finansal Raporlamanın Tespitinde Veri Madenciliğine Dayalı Yöntemlerin}

\section{Kullanımı}

Hileli finansal raporlamanın tespitinde farklı bir takım yöntemler kullanılabilmektedir. Analitik inceleme prosedürleri, Benford Yasası, tahakkuk esaslı modeller bu yöntemlerden bazılarıdır. Son dönemlerde yapılan akademik araştırmalarda ise veri madenciliğine dayalı yöntemlerin de finansal tablo hilelerinin tespitinde kullanılabileceği belirtilmektedir. Literatürde finansal tablo hilelerinin tespit edilmesinde kullanılan ve araştırmacılar tarafından başarılı olduğu sonucuna ulaşılan veri madenciliğine dayalı yöntemler aşağıda açıklanmıştır.

HFR'nin tespitinden sıkça kullanılan derin öğrenme (Deep Learning) algoritması, yapay sinir ağlarının işlevlerini temel olarak alan bir tür makine öğrenme algoritmasıdır. Derin öğrenme, büyük verileri etkili bir şekilde kullanarak verimli sonuçlar elde etmektedir. Derin öğrenme, sınıflandırma özellikleri ile görevlerini direkt veri üzerinden gerçekleştirmektedir. Bu modeller, insan düzeyinde öğrenmeyi başarmak ve bu seviyeyi aşmak için çeşitli sayıda sinir ağı mimarisi kullanılarak eğitilebilir (Şişmanoğlu vd., 2020: 437).

Bir diğer yöntem olan yapay sinir ağı (YSA) algoritması ise verileri sınıflandırmak ve tahmin etmek için insan beynini taklit eden bir makine öğrenme algoritması türüdür. YSA, nöronlardan ya da düğümlerden oluşur ve birkaç farklı düğümü ve bunlarla ilgili bilgileri tek bir çıkış sinyalinde birleştirir. Veri sınıflandırması için tipik bir sinir ağı girdi, gizli ve çıktı olmak üzere üç katmandan oluşur (Liou, 2008: 653).

Karar ağacı (Decision Tree) algoritması, bağımlı değişken değerinin tahmini bir bağımsız değişken verisinin değerlerini kullanarak nasıl tahmin edilebileceğini, ikili ağaç olarak gösteren mantıksal makine öğrenme modellerinden biridir (Demirci, 2019: 1116).

J48 algoritması ise doğrusal olmayan ve küçük verilerin sınıflandırma işlemi için Quinalan tarafından geliştirilen bir C4.5 karar ağacıdır. J48 algoritmasında temel fikir, karar ağaçlarınca üretilen kurallar uygulanarak sınıflandırma işleminin yapılmasıdır (Eraldemir vd., 2017: 1253). 
Rastgele orman (Random Forest) algoritması, büyük verilerin sınıflandırılabilmesi için Leo Breiman ile Adele Cutler'in geliştirdiği makine öğrenme algoritmalarından biridir. Rastgele orman, sınıflandırma oranını iyileştirmek ve yoğun olan uyum problemini halledebilmek için aynı veri setinin farklı kısımlarında eğitilen karar ağaçları yetiştirir (Eraldemir vd., 2017: 1253).

Navie Bayes algoritması, pratik öğrenme problemlerinde nadiren geçerli olan bir varsayıma dayanır. Navie Bayes, bir tahminin türetilebilmesi için kullanılan niteliklerin tahmin edilen değeridir. Birkaç pratik sınıflandırma görevi için Navie Bayes, önemli ölçüde düşük hata üretir (Frank et al., 2000: 5).

Lojistik Regresyon (LR), ikili bağımlılığı modellemek için kullanılan doğrusal olmayan bir makine öğrenme algoritmasıdır. Yani sınıflandırma değişkeni sadece iki değere sahip olabilir anlamına gelmektedir. Veriler, doğru-yanlış, başarılı-başarısız, hileli-hilesiz gibi tanımlanabilmektedir. Lojistik regresyon, kolayca yorumlanma avantajına sahiptir ve HFR'nin tespit edilmesinde sıklıkla kullanılan bir veri madenciliği türüdür (Liou, 2008: 653).

Destek vektör makineleri (SVM), veri odaklı araştırma alanlarında kullanılan bir makine öğrenme algoritmasıdır. Temeli istatiksel öğrenme teorilerinden oluşan SVM, teori olarak iki ayrı sınıfa ait olan örnekleri doğrusal olarak en iyi ayıran destek vektörlerine dayanmaktadır (Demirci, 2019: 1115).

K-En yakın komşu (KNN) yöntemi, sınıfları bilinen bir örnek sınıfındaki gözlem değerlerinden faydalanarak örneğe eklenecek yeni gözlemin hangi kümeye ait olduğunu belirlemek amacı ile kullanılan yöntem türüdür (Kolyiğit vd., 2012: 424).

AdaBoost, toplama yöntemi olarak bilinen makine öğrenme algoritmalarından biridir. AdaBoost Algoritması, birçok güçsüz öğrenme algoritmalarını birleştirerek daha güçlü bir öğrenme algoritması oluşturmaya çalışır. Bu yüzden sıklıkla kullanılan boosting algoritmaları arasında yer alır (Freund and Schapire, 1999: 772).

\section{Yöntem}

Çalışmanın amacı, hile riski taşıdığı bağımsız denetim raporları ve SPK tarafından yapılan incelemelerle tespit edilen finansal tabloların veri madenciliğine dayalı yöntemler kullanılarak finansal oranlar aracılığıyla tespit edilmesi ve buna bağlı olarak bu yöntemlerin doğru sınıflandırma başarısının ortaya çıkarılmasıdır.

\subsection{Araştırmanın Kapsamı}

Çalışmanın kapsamına BİST Tekstil, Giyim Eşyası ve Deri sektöründe hisse senetleri işlem gören şirketler alınmıştır. Bu kapsamda şirketlerin 2015-2019 yıllarına ilişskin beş döneme ait yıllık finansal tabloları, bağımsız denetim raporları ve SPK bültenleri incelenmiştir. Çalışma 
kapsamında incelenen şirketlerin endekste işlem görme durumlarına göre sayıları Tablo 1'de gösterilmiştir.

Tablo 1. Araştırma Kapsamındaki Şirketlerden Y1llar İtibariyle Tekstil Sektöründe İşlem Gören Şirket Sayıları

\begin{tabular}{|c|c|}
\hline Ylllar & Şirket Saylsı \\
\hline 2015 & 30 \\
\hline 2016 & 27 \\
\hline 2017 & 27 \\
\hline 2018 & 24 \\
\hline 2019 & 24 \\
\hline Toplam & 132 \\
\hline
\end{tabular}

Tablo 1'e göre yıllar itibariyle şirket sayıları arasında farklılıklar bulunmaktadır. Bu farklılığın sebebi, şirketin sektör değişikliği yapmış olması, kottan çıkarılmış olması ya da yakın izlemeye alınmış olmasıdır. Hisse senedi BİST’te işlem görmeyen şirketlerin finansal tabloları, işlem görmediği yılda değerlendirmeye alınmamıştır. Başka bir ifadeyle BİST Tekstil sektöründe işlem görmekte olan şirketlerin söz konusu 5 yılda borsada işlem gördükleri dönemlere ait finansal tabloları, bağımsız denetim raporları ve haftalık SPK Bültenleri çalışma kapsamında analiz edilmiştir. Tablo 1'de görüldüğü üzere söz konusu döneme ilişkin finansal tablo sayısı 132'dir. Ancak, farklı şirketlerin farklı dönemlerine ait 5 finansal tabloya ulaşılamaması sebebiyle 127 finansal tablo seti ve bu finansal tablolara ilişkin bağımsız denetim raporları çalışma kapsamında incelenmiştir.

\subsection{Araștırmanın Yöntemi ve Verilerin Analizi}

Çalışmanın amacına uygun olarak öncelikle hile riski taşıyan finansal tabloların ortaya çıkarılması gerekmektedir. Bu tespitin yapılabilmesi için farklı araştırmacılar tarafından farklı yöntemler kullanılmıştır. Bazı araştırmacılar (Spathis 2002, Kotsiantis vd. 2006, Ata-Seyrek 2009, Chen 2011, Terzi 2012) hile riski taşıyan finansal tabloların tespit edilmesinde bağımsız denetim raporlarından yararlanmışlardır. Bazı araştırmacılar (Amara vd. 2013, Liu vd. 2015, Craja vd. 2020) ise düzenleyici ve denetleyici kuruluşların denetimleri esnasında kayda aldıkları ve rapor haline getirdikleri usulsüzlükleri inceleyerek hile durumunu tespit etmeye çalışmışlar ya da her iki yöntemi birden uygulamışlardır.

$\mathrm{Bu}$ çalışmada hile riski taşıyan finansal tabloların belirlenebilmesi için hem bağımsız denetim raporları hem de haftalık SPK bültenleri incelenmiştir. Çalışmada her iki yöntemin de kullanılmasının sebebi, bağımsız denetim çalışmalarında tespit edilemeyen usulsüzlüklerin SPK tarafından yapılan denetimler esnasında ortaya çıkarılabilmiş olma ihtimalinden kaynaklanmaktadır (Kıymık vd. 2015: 769). Yapılan incelemeler neticesinde hile riski taşıyan 
(HRV) finansal tablolar 1, hile riski taşımayan (HRY) finansal tablolar ise 0 olarak kodlanmıştır.

Araştırmanın ikinci aşamasında literatürde hileli finansal raporlamayı açıklamakta kullanılan 12 adet finansal oran belirlenmiş ve 127 finansal tablo seti için bu oranlar hesaplanmıştır. Çalışmada kullanılmak üzere belirlenen finansal oranlar aşağıda verilmiştir;

1. Brüt Kâr / Aktif Toplam

2. Çalışma Sermayesi / Aktif Toplam

3. Net Kâr / Aktif Toplam

4. Satışlar / Aktif Toplam

5. Stoklar / Satışlar

6. Borç/Öz Sermaye Oranı

7. Cari Oran

8. Kaldıraç Oranı

9. Faizin Kazanılma Sayıs1

10. Duran Varlıklar/Devamlı Sermaye Oranı

11. Asit-Test Oranı

12. Finansman Oran1

Araştırmanın üçüncü aşamasında ise hile riski taşıyan finansal tabloların tespitinde veri madenciliğine dayalı yöntemler kullanılarak bu yöntemlerin hile riskini tespit etmedeki gücü test edilmiştir. Çalışmada, seçilen finansal oranlara uygun olarak kullanılacak olan veri madenciliği yöntemlerinin tespit edilebilmesi için ulusal ve uluslararası literatür (Bell ve Carcello 2000, Koskivaara 2004, Kotsiantis vd. 2006, Ata ve Seyrek 2009, Chen 2011, Amara vd. 2013, Kırlığlu ve Ceylan 2014, Liu vd. 2015, Söylemez ve Türkmen 2017, Kopun 2018, Ye vd. 2019, Craja vd. 2020) incelenmiş olup, söz konusu çalışmalarda finansal tablo hilelerinin tespit edilmesinde kullanılan ve araştırmacılar tarafından anlamlı olduğu tespit edilen 10 yöntem belirlenmiştir. Çalışmada kullanılacak olan veri madenciliğine dayalı yöntemler şunlardır;

1. Derin Öğrenme

2. Yapay Sinir A $\breve{g} 1$

3. Karar Ağacı Algoritması

4. J48 Algoritmas1

5. Rastgele Orman Algoritmas1

6. Destek Vektör Makineleri

7. K-En Yakın Komşu 
8. AdaBoost Algoritmas1

9. Navie Bayes

10. Lojistik Regresyon

\section{Araștırmanın Bulguları}

Araştırma bulguları aşağıdaki başlıklar altında açıklanmıştır.

\subsection{Hileli Finansal Raporlamanın Tespitine İlişkin Bulgular}

Çalışma kapsamındaki finansal tabloların hile riski taşıyıp taşımadıklarını tespit etmek amacıyla ilgili şirketlerin 2015-2019 dönemlerine ait bağımsız denetimden geçmiş finansal tabloları ve bağımsız denetim raporları incelenmiştir. İncelenen finansal tablolara ilişkin bağımsız denetim raporlarına göre; olumsuz görüş, görüş bildirmekten kaçınma ve şartlı görüş bildirilen finansal tabloların hile riski taşıdığı; olumlu görüş bildirilen bağımsız denetim raporlarına ilişkin finansal tabloların ise hile riski taşımadığı varsayılmıştır. Çalışma kapsamındaki şirketlerin finansal tablolarına yıllar itibariyle bağımsız denetçiler tarafından bildirilen görüş türleri Tablo 2'de gösterilmiştir.

Tablo 2. Bağımsız Denetçiler Tarafından Bildirilen Görüşler

\begin{tabular}{|c|c|c|c|}
\hline Yıllar & Olumlu Görüşs & $\begin{array}{c}\text { Olumsuz, Sartlıve } \\
\text { Görüş Bildirmekten } \\
\text { Kaçınma }\end{array}$ & Toplam \\
\hline 2015 & 19 & 10 & 29 \\
\hline 2016 & 20 & 6 & 26 \\
\hline 2017 & 20 & 4 & 24 \\
\hline 2018 & 17 & 7 & 24 \\
\hline 2019 & 16 & 8 & 24 \\
\hline Toplam & 92 & 35 & 127 \\
\hline
\end{tabular}

Tablo 2'den anlaşıldığı gibi çalışma kapsamındaki şirketlerin BİST'te işlem gördükleri 2015-2019 dönemlerine ait toplam 127 finansal tabloya ilişkin bağımsız denetim raporu incelenmiştir. Bağımsız denetim kuruluşlarınca gerçekleştirilen denetimler sonucunda 92 finansal tabloya olumlu görüş bildirilmiş ve bu finansal tabloların hile riski taşımadığı kabul edilmiştir. Bağımsız denetim neticesinde 35 finansal tabloya olumsuz veya şartlı görüş bildirilmiş ya da görüş bildirmekten kaçınılmıştır. Bu finansal tabloların hile riski taşıdığı kabul edilmiştir.

Olumsuz veya şartlı görüş bildirilen ve görüş bildirmekten kaçınılan bağımsız denetim raporlarının hile riskine ilişkin dayanakları aşağıda maddeler halinde özetlenmiştir; 
- Üretim faaliyetleriyle ilgili kapasite kullanım oranları hesaplamasının yapılmaması ve bu yüzden sabit genel üretim maliyetinin farklılığının finansal tablolara olan etkisinin belirlenememesi,

- Değer düşüklüğüne uğramış olan maddi duran varlıklara karşılık ayrılmaması,

- Maddi olmayan duran varlıkların TMS'nin izin vermediği bir ölçüte göre değerlemeye tabi tutulmas1,

- Alacaklar için uygun ve yeterli bir şekilde karşılık ayrılmaması,

- Esas sermayenin 2/3'ünün karşılıksız kalmış olması durumunun önüne geçilebilmesi için uygun olmayan varlık değerlemesi yapılması,

- Borçların TMS ve TFRS'ye uygun olmayan şekillerde değerlemeye tabi tutulması,

- Grup şirketlerinin konsolide finansal tablolara dahil edilmemesi,

- Uygun olmayan stok değerlemesi,

- Hukuki aşaması devam eden vergi ceza ve borçlar için karşılık ayrılmaması,

- İlişkili taraflardan olan alacakların SPK kriterlerine uyum sağlamak amacı ile olduğundan düşük raporlanması,

- İlişkili taraflardan olan alacak tutarında söz konusu şirket tarafından raporlanan tutarla ana ortaklık tarafindan raporlanan tutar arasında farklılık bulunması.

Bağımsız denetim raporlarından elde edilmiş olan bu hususların genel kabul görmüş muhasebe ilkeleri ve muhasebe standartlarına aykırı olduğu ve söz konusu aykırılıkları içeren finansal tabloların hile riski taşıdığının kabul edilmesinin, ACFE veya SPK tarafından yapılmış olan hileli finansal raporlama sınıflandırmasına uygun olduğu düşünülmektedir.

Çalışmada hile riski taşıyan finansal tabloların tespiti için ayrıca SPK haftalık bültenleri de incelenmiştir. Haftalık bültenler incelenirken bazı usulsüz işlemlerin gerçekleştiği tarihten çok sonra da tespit edilebildiği anlaşılmıştır (Kıymık vd. 2015: 772). Bu sebeple çalışma kapsamındaki şirketlerin 2015-2019 yıllarına ait finansal tabloları incelenirken, haftalık SPK bültenleri 2015-2020 yıllarını kapsayacak şekilde değerlendirilmiştir. İncelemeler neticesinde SPK tarafından tespit edilmiş ve farklı tutar ve şekillerde cezalandırılmış olan usulsüz işlem ve durumlar Tablo 3'te gösterilmiştir.

Tablo 3. Haftalık SPK Bültenleri Aracılığıyla Tespit Edilen Usulsüz İşlem ve Durumlar

\begin{tabular}{|l|c|}
\hline Usulsüzlüğü Konu Olan İşlem ve Durumlar & Gözlem Sayısı \\
\hline Özel durum açıklamalarının zamanında yapılmaması & 3 \\
\hline Kamuya açıklanması gereken durumların zamanında ya da hiç açıklanmaması & 8 \\
\hline Bazı finansal işlemlerin 6362 sayılı SPK ve ilgili mevzuata aykırılık teşkil etmesi & 16 \\
\hline
\end{tabular}




\begin{tabular}{|l|c|} 
Finansal raporların ilgili süre içerisinde KAP'a bildirilmemesi & 2 \\
\hline Kâr dağıtımının zamanında yapılmaması & 3 \\
\hline Pay piyasasının arz ve talebi ile fiyatı hakkında yanıltıcı olunması & 7 \\
\hline Kamuyu yanıltıcı nitelikte beyanda bulunulması & 3 \\
\hline Finansal tabloların dipnotlarında yanıltıcı açıllamalarda bulunulması & 2 \\
\hline Finansal tablo dipnotlarında dönemler itibariyle tutarsızlık olması & 4 \\
\hline $\begin{array}{l}\text { Finansal tabloların dipnotlarında ilişkili taraf açıklamalarının TMS 24'e aykırı } \\
\text { olması }\end{array}$ & 3 \\
\hline $\begin{array}{l}\text { İştiraklerin TMS/TFRS hükümlerine aykırı bir şekilde kayıt yapılması ya da } \\
\text { değerlemesi }\end{array}$ & 1 \\
\hline $\begin{array}{l}\text { TMS/TFRS hükümlerine göre gerekli şartların gerçekleşmemesine rağmen gelir } \\
\text { kaydı yapılması }\end{array}$ & 2 \\
\hline Şirket birleşmeleri sırasında yanlış ve yanıltıcı açılamalarda bulunulması & 1 \\
\hline
\end{tabular}

Tablo 3'e göre SPK tarafından yapılan denetimlerde örneklem kapsamındaki şirketlere ilgili dönemlerde, farklı usulsüzlükler sebebiyle cezalar verildiği görülmektedir. Bu cezalar, genel olarak şirketlerin kamuya açıklaması gereken bilgi ve finansal tablolarını zamanında ya da hiç açıklamamış olmasından kaynaklanmaktadır. Tablo 3'te finansal tablo usulsüzlüğü olarak kabul edilebilecek hususlar, finansal tablo dipnotlarında yanıltıcı bilgi verilmesi ve bazı mali işlemlerin TMS/TFRS'ye aykırı olarak muhasebeleştirilmiş olmasıdır. Yapılan incelemede SPK tarafından cezalandırılan bu muhasebe usulsüzlüklerinin, finansal tabloların bağımsız denetiminde de tespit edildiği ve ilgili finansal tablolara bu yönde görüş bildirildiği anlaşılmıştır. Bu sebeple araştırma kapsamında incelenen 127 finansal tablonun 35'inin hile riski taşıdığı, kalan 92'sinin ise hile riski taşımadığı sonucuna ulaşılmıştır.

\subsection{Hileli Finansal Raporlamayı Açıklamada Kullanılan Finansal Oranlar}

Gerek ulusal gerekse uluslararası literatür incelemesi neticesinde, hileli finansal raporlamayı açıklamada istatistiki açıdan anlamlı olduğu sonucuna ulaşılan 12 farklı finansal oran tespit edilmiştir. Araştırma kapsamında incelenen 127 finansal tablo setinden elde edilen oranlar Tablo 4'te gösterilmiştir.

Tablo 4. Finansal Oran Ortalamaları

\begin{tabular}{|l|l|r|r|}
\hline \multicolumn{2}{|c|}{ Değişkenler } & \multicolumn{1}{c|}{$N$} & \multicolumn{1}{c|}{ Ortalama } \\
\hline \multirow{2}{*}{ Cari Oran } & HRY & 92 & 1,1902 \\
\cline { 2 - 5 } & HRV & 35 & 0,9163 \\
\hline \multirow{3}{*}{ Asit-Test Oranı } & HRY & 92 & 0,6734 \\
\cline { 2 - 5 } & HRV & 35 & 0,5131 \\
\hline \multirow{2}{*}{ Kaldıraç Oranı } & HRY & 92 & 0,5778 \\
\cline { 2 - 5 } & HRV & 35 & 0,7179 \\
\hline
\end{tabular}




\begin{tabular}{|l|l|r|r|}
\multirow{2}{*}{ Finansman Oranı } & HRY & 92 & 0,7331 \\
\cline { 2 - 4 } & HRV & 35 & 0,3948 \\
\hline \multirow{2}{*}{ Faizin Kazanılma Sayısı } & HRY & 92 & 1,3462 \\
\cline { 2 - 4 } & HRV & 35 & 0,0550 \\
\hline \multirow{2}{*}{ Çüt Kâr/Aşma Sermayesi/Aktif Toplam } & HRY & 92 & 0,2011 \\
\cline { 2 - 4 } & HRV & 35 & 0,1207 \\
\hline \multirow{2}{*}{ Net Kâr/Aktif Toplam } & HRY & 92 & 0,0707 \\
\cline { 2 - 4 } & HRV & 35 & $-0,0429$ \\
\hline \multirow{2}{*}{ Satışlar/Aktif Toplam } & HRY & 92 & 0,0339 \\
\cline { 2 - 4 } & HRV & 35 & $-0,0345$ \\
\hline \multirow{2}{*}{ Stoklar/Satışlar } & HRY & 92 & 0,7755 \\
\cline { 2 - 4 } & HRV & 35 & 0,5670 \\
\hline \multirow{2}{*}{ Toplam Borç/Öz Kaynaklar } & HRY & 92 & 0,2517 \\
\cline { 2 - 4 } & HRV & 35 & 0,3649 \\
\hline \multirow{2}{*}{ Duran Varlıklar/Devamlı Sermaye Oranı } & HRY & 92 & 1,3640 \\
\cline { 2 - 4 } & HRV & 35 & 2,5329 \\
\hline & HRY & 92 & 0,8826 \\
\cline { 2 - 4 } & HRV & 35 & 1,0852 \\
\hline
\end{tabular}

Tablo 4'te gösterilen oranlar, şirket gruplarının ilgili finansal tablo kalemlerinin toplamları üzerinden hesaplanmıştır. Tablodan da anlaşılacağı üzere hile riski taşıyan finansal tablolar ile hile riski taşımayan finansal tablolardan elde edilen oranların genel olarak farklılaştığı göze çarpmaktadır. Hileli finansal raporlama yapıldığı tespit edilen dönemlere ilişkin finansal tablolarda; finansal tablolarının hile riski taşıdığı kabul edilen şirketlerin net çalışma sermayesinin yetersiz olduğu, genel olarak zarar raporladıkları, öz kaynaklarının hile riski diğer şirket grubuna göre oldukça düşük olduğu, toplam borçlarının öz kaynaklara oranının diğerlerine göre iki katı olduğu sonucuna ulaşılmıştır.

\subsection{Veri Madenciliğine Dayalı Yöntemler Aracılı̆̆ıla Hileli Finansal Raporlamanın Tespiti}

Hileli finansal raporlamanın tespitine yönelik kullanılan tüm algoritmalara ilişkin yapılan analizler neticesinde ortaya çıkan sınıflandırma sonuçları Tablo 5'te gösterilmiştir.

Tablo 5. Çalışmada Kullanılan Algoritmalarının Sınıflandırma Sonuçları

\begin{tabular}{lrrrr}
\hline & Hassasiyet & Kesinlik & F-Ölçütü & ROC \\
\hline J48 & 0,841 & 0,843 & 0,831 & 0,816 \\
\hline Derin Öğrenme & 0,841 & 0,843 & 0,831 & 0,726 \\
\hline $\begin{array}{l}\text { Destek Vektör } \\
\text { Makineleri }\end{array}$ & 0,824 & 0,827 & 0,811 & 0,721 \\
\hline Lojistik Regresyon & 0,820 & 0,827 & 0,817 & 0,683 \\
\hline
\end{tabular}




\begin{tabular}{lllll} 
K-En Yakın Komşu & 0,829 & 0,819 & 0,794 & 0,672 \\
\hline Yapay Sinir Ağ & 0,813 & 0,819 & 0,804 & 0,722 \\
\hline Adaboost & 0,805 & 0,811 & 0,794 & 0,821 \\
\hline Rastgele Orman & 0,794 & 0,803 & 0,796 & 0,813 \\
\hline Karar Ağac1 & 0,785 & 0,795 & 0,786 & 0,769 \\
\hline Navie Bayes & 0,733 & 0,756 & 0,727 & 0,745 \\
\hline
\end{tabular}

Tablo 5'te yer alan oranların hesaplanması aşağıdaki gibi olup verilerin yorumlanmasında aşağıdaki tanımlamalar esas alınmıştır (Tokmak ve Kıraç, 2021: 75).

Formüllerde yer alan kısaltmaların açıklamaları şu şekildedir;

TP (True Positive) : : Gerçek Pozitif

TN (True Negative) : : Gerçek Negatif

FP (False Positive) : Yanlış Pozitif

FN (False Negative) : Yanlış Negatif

Hassasiyet: Gerçek pozitif değerlerin ne kadarının doğru olduğunu ifade eden duyarlılık (recall) değeridir. Aşağıdaki formülle hesaplanır;

Hassasiyet $=\mathrm{TP} /(\mathrm{TP}+\mathrm{FN})$

Kesinlik: Pozitif olarak tahmin edilen örneklerin gerçekte ne kadarının pozitif olduğunu ifade eden kesinlik (precision) değeridir. Aşağıdaki formülle hesaplanır;

Kesinlik $=\mathrm{TP} /(\mathrm{TP}+\mathrm{FP})$

F-Ölçütü: Hassasiyet ve kesinlik değerlerinin ağırlıklı ortalamasını gösteren ölçüttür (Ye et al., 2019: 5). Aşağıdaki formülle hesaplanır;

F Ölçütü $=(2 \times$ Hassasiyet $x$ Kesinlik $) /($ Duyarlılık + Kesinlik $)$

ROC Ĕ̆risi: Öngörülen ve karşılaştırılan bir sınıflandırmadaki gerçek hedef değerdir.

Matris: Analizde oluşturulan sınıflandırıcının iki nokta arasındaki yakınlık, iki ayrı verinin aynı anda oluşma sayısının oranı olarak tanımlanır. Farklı sınıfların dizilerinin ne kadar iyi tanıyabildiğini analiz etmek için yararlı bir araçtır (Sharma and Jain, 2013: 1929-1930). Ayrıca tüm algoritmalarda 10 kat çapraz doğrulama test modu kullanılmıştır. Analiz sonuçlarına göre \%70 ve üzerinde değere sahip olan modeller başarılı kabul edilmiştir.

Tablo 5'te hile riski taşımadığı kabul edilen 92 finansal tablo ve hile riski taşıdığı kabul edilen 35 finansal tablodan elde edilen oranlar kullanılarak veri madenciliğine dayalı yöntemlerin hile riski bakımından finansal tabloları doğru sınıflandırma gücü, başarı oranına göre gösterilmiştir. Buna göre doğru sınıflandırma başarısının en yüksek olduğu yöntemlerin J48 ve Derin Öğrenme algoritmaları olduğu anlaşılmaktadır. Bu modellerde \% 84,1 hassasiyet değerine, \% 84,3 kesinlik değerine ve \% 83,1 F1-skoru değerine ulaşılmıştır. İlgili değerlerin 
verdiği sonuçlar neticesinde tüm algoritmaların hata matrisi sonuçları ise Tablo 6'da gösterilmiştir.

Tablo 6. Çalışmada Kullanılan Algoritmalarının Hata Matrisi Sonuçları

\begin{tabular}{lrrrrr}
\hline & Sayı $(n)$ & HRY & HRV & $\begin{array}{r}\text { Doğru } \\
\text { Sintflandirma }\end{array}$ & Başarı Oranı \\
\hline J48 & 127 & 104 & 23 & 107 & $84,25 \%$ \\
\hline Deep Learning & 127 & 104 & 23 & 107 & $84,25 \%$ \\
\hline Logistic Regression & 127 & 102 & 25 & 105 & $82,68 \%$ \\
\hline SVM & 127 & 106 & 21 & 105 & $82,68 \%$ \\
\hline YSA & 127 & 105 & 22 & 104 & $81,89 \%$ \\
\hline KNN & 127 & 111 & 16 & 104 & $81,89 \%$ \\
\hline AdaBoost & 127 & 106 & 21 & 103 & $81,10 \%$ \\
\hline Random Forest & 127 & 99 & 28 & 102 & $80,31 \%$ \\
\hline Decision Tree & 127 & 100 & 27 & 101 & $79,53 \%$ \\
\hline Navie Bayes & 127 & 109 & 18 & 96 & $75,59 \%$ \\
\hline
\end{tabular}

Tablo 6'da görüldüğü üzere en başarılı yöntemler olan J48 ve Derin Öğrenme algoritmalarının hata matrisi sonucuna göre, toplam 127 finansal tablodan 107'si doğru sınıflandırılarak modeller \% 84,25 başarı göstermiştir. Bu modelleri lojistik regresyon ve destek vektör makineleri izlemiş ve bu modellerin başarı oranı ise \% 82,68 olarak gerçekleşmiştir. Hata matrisi sonuçlarına göre hile riski taşıyan ve taşımayan finansal tabloların tahmin edilmesinde en düşük başarı düzeyine sahip yöntemler ise Karar Ăgacı $(\% 79,53)$ ve Navie Bayes $(75,59)$ yöntemleri olmuştur. Genel olarak tüm modeller göz önünde bulundurulduğunda ise araştırmada kullanılan veri madenciliğine dayalı yöntemlerin, seçilmiş bazı finansal oranlar aracılığıyla hile riski taşıyan/taşımayan finansal tabloları sınıflandırmada başarılı olduğu sonucuna ulaşılmıştır.

\section{Sonuç}

Geçmişten günümüze muhasebe hileleri gerek iş dünyasının ve gerekse de akademisyenlerin gündeminde yerini almış ve almaya devam etmektedir. Muhasebe hilelerinin sonucu olarak ortaya çıkan hileli finansal raporlamanın önlenmesine/azaltılmasına yönelik düzenlemeler, ulusal ve uluslararası düzenleyici kuruluşlar tarafından yapılmaktadır. Sermaye piyasalarının etkinliğini ve güvenilirliğini etkileyen bir unsur olarak karşımıza çıkan hileli finansal raporlama konusunda yapılan akademik çalışmaların sayısı da günden güne artmaktadır. Konuyla ilgili yapılan çalışmaların bir kısmı hileli finansal raporlamanın tespiti ile ilgilidir. Literatürde hileli finansal raporlamanın tespiti ile ilgili farklı yöntemlerin kullanıldığı çok sayıda çalışma bulunmaktadır. Bunların bir kısmı da veri madenciliğine dayalı yöntemlerin hileli finansal raporlamanın tespitinde kullanımı ile ilgilidir. 
BİST Tekstil, Giyim Eşyası ve Deri sektöründe hisse senetleri işlem gören şirketlerin, hileli finansal raporlama uygulamalarının veri madenciliğine dayalı yöntemler kullanılarak finansal oranlar aracılığıyla tespit edilmesi ve buna bağlı olarak bu yöntemlerin hile riskini tespit etmedeki gücünün ortaya çıkarılmasını amaçlayan bu çalışmanın sonuçlarını aşağıdaki gibi özetlemek mümkündür.

Araştırma kapsamında, 2015-2019 yılları arasında BIST Tekstil, Giyim Eşyası ve Deri Sektöründe hisse senetleri işlem görmüş olan şirketlerin bağımsız denetimden geçmiş 127 finansal tablo seti ve bağımsız denetim raporları incelenmiştir. Bağımsız denetim neticesinde finansal tabloların 92'sine olumlu görüş bildirildiği tespit edilmiş ve bu finansal tabloların hile riski taşımadığı kabul edilmiştir. Kalan 35 finansal tabloya ise olumsuz veya şartlı görüş bildirildiği ya da görüş bildirmekten kaçınıldığı tespit edilmiş ve bu finansal tabloların hile riski taşıdığı kabul edilmiştir. Bağımsız denetim raporlarının dayanakları incelendiğinde; bağımsız denetim esnasında tespit edilen hususların genel kabul görmüş muhasebe ilkeleri ve muhasebe standartlarına aykırı olduğu ve söz konusu aykırılıkları içeren finansal tabloların hile riski taşıdığının kabul edilmesinin, ACFE veya SPK tarafından yapılmış olan hileli finansal raporlama sınıflandırmasına uygun olduğu düşünülmektedir.

Ulusal ve uluslararası literatür incelenerek hileli finansal raporlamayı açıklamada istatistiki açıdan anlamlı olduğu sonucuna ulaşılan 12 finansal oran belirlenmiş ve ilgili dönem ve şirketler itibariyle bu oranlar hesaplanmıştır. Çalışmada bu oranlar, şirket gruplarının ilgili finansal tablo kalemlerinin toplamları üzerinden hesaplanmıştır. Araştırma bulgularına göre hile riski taşıdığı kabul edilen finansal tablolarda nispeten net çalışma sermayesinin yetersiz olduğu, genel olarak zarar raporlandığı ve toplam borçların öz kaynaklara oranının diğerlerine göre iki katı olduğu sonucuna ulaşılmıştır.

Araştırmanın amacına uygun olarak, hileli finansal raporlamanın tespitinde ulusal ve uluslararası literatürde sıklıkla kullanılmış olan veri madenciliğine dayalı 10 yöntem belirlenmiş ve oluşturulan modellerle yöntemlerin hile riski içeren/içermeyen finansal tabloları sınıflandırmadaki başarısı test edilmiştir. Tüm algoritmalarda 10 kat çapraz doğrulama test modu kullanılmış olup \%70 ve üzerinde başarı oranına sahip olan modeller başarılı kabul edilmiştir.

Yapılan analiz sonuçlarına göre sınıflandırma amacıyla kullanılan tüm modellerin hile riski içeren ve içermeyen finansal tabloları doğru sınıflandırmadaki başarı oranlarının \% 70'in üzerinde olduğu sonucuna ulaşılmıştır. Araştırma bulgularına göre en başarılı yöntemler J48 ve Derin Öğrenme yöntemleri olup bu modellerin başarı oranı \% 84,25 olarak gerçekleşmiştir. Başka bir anlatımla bu yöntemler kullanılarak oluşturulan modeller araştırma kapsamındaki 
toplam 127 finansal tablonun 107'sini doğru sınıflandırmayı başarmışlardır. Bu modelleri lojistik regresyon ve destek vektör makineleri izlemiş ve bu modellerin başarı oranı ise \% 82,68 olarak gerçekleşmiştir. Hata matrisi sonuçlarına göre hile riski taşıyan ve taşımayan finansal tabloların tahmin edilmesinde en düşük başarı düzeyine sahip yöntemler ise Karar Ağacı (\% $79,53)$ ve Navie Bayes $(75,59)$ yöntemleri olmuştur. Genel olarak tüm modeller göz önünde bulundurulduğunda ise araştırmada kullanılan veri madenciliğine dayalı yöntemlerin, seçilmiş bazı finansal oranlar aracılığıyla hile riski taşıyan/taşımayan finansal tabloları sınıflandırmada başarılı olduğu sonucuna ulaşılmıştır.

Araştırma konusu ile ilgili olarak ulusal ve uluslararası literatürde veri madenciliğine dayalı yöntemler kullanılarak finansal tablo hilelerinin tespit edilmesi ile ilgili farklı yöntemler kullanılarak yapılan birçok araştırma bulunmaktadır. Ancak yapılan incelemede, derin öğrenme modelinin ulusal ve uluslararası literatürde çok az çalışmada kullanıldığı tespit edilmiş ve araştırma bulgularına göre derin öğrenme modelinin en başarılı yöntemlerden biri olduğu sonucuna ulaşılmıştır. $\mathrm{Bu}$ bakımdan çalışmanın gelecek çalışmalara 1 şık tutacağı düşünülmektedir. 


\section{KAYNAKÇA}

ACFE (2020). Report to The Nations: 2020 Global Study On Occupational Fraud And Abuse.

AICPA. Consideration of Fraud in a Financial Statement Audit, https://www.aicpa.org/ (21.12.2020).

Altıntaş, N. N. (2010). Denetimde Hata ve Hile. Ístanbul Üniversitesi Sosyal Bilimler Dergisi, 1, 151-161.

Amara, I., Amar, A. \& Jarbou1, A. (2013). Detection of Fraud in Financial Statements: French Companies as a Case Study, International Journal of Academic Research in Accounting, Finance and Management Sciences, 3(3), 40-51.

Ata, H. A. \& Seyrek, İ. H. (2009). The Use Data Mining Techniques In Detecting Fraudulent Financial Statements: An Application On Manufacturing Firms. Süleyman Demirel Üniversitesi I.I.B.F. Dergisi, 14(2), 157 170.

Bell, T. \& Carcello, J. (2000). A Decision Aid For Assessing The Likelihood Of Fraudulent Financial Reporting, Auditing: A Journal of Practice \&Theory, 19(1), 169-184.

Can, A. V. (2010). Krizin Muhasebesi ve Muhasebenin Krizi. Mali Çözüm Dergisi, 97, 21-48.

Chen, M. (2011). Predicting Corporate Financial Distress Based on Integration of Desicion Tree Classification and Logistic Regression. Expert Systems With Applications, 38(9), 11261-11272.

Craja, P. Kim, A. \& Lessmann, S. (2020). Deep Learning for Detecting Financial Statement Fraud. Decision Support Systems, 139, 1-13.

Çıtak, N. (2009). Yaratıcı Muhasebe Hileli Finansal Raporlama Mıdır?. Mali Çözüm Dergisi, 91, 81-112.

Demir, M., Kısakürek, M. M. \& Arslan, Ö. (2019). İç Denetim Siteminin Hileli Finansal Raporlamayı Önlemedeki Rolüne Yönelik Bağımsız Denetçiler Üzerinde Bir Araştırma. Muhasebe ve Finansman Dergisi, Sayı 82, 111-134.

Demirci, M. (2019). Destek Vektör Makineleri ve M5 Karar Ağacı Yöntemleri Kullanılarak Yağış-Akış İlişkisinin Tahmini, Dicle Üniversitesi Mühendislik Fakültesi Mühendislik Dergisi, 10(3), 1113-1124.

Dutta, I., Dutta, S. \& Raahemi B. (2017). Detecting Financial Restatements Using Data Mining Techniques. Expert Systems With Applications, 90, 374-393.

Eraldemir, S., Arslan, M. \& Yıldırım, E. (2017). Hilbert Huang Dönüşümü Uygulanan EEG İşaretlerinden J48 ve Rastgele Orman Sınıflandırıcılarının Karşılaştırılması. International Advanced Researches\&Engineering Congress, 1250-1256.

Frank, E., Trigg, L., Holmes, G. \& Witten, I. (2000). Technical Note: Navie Bayes For Regression. Kluwer Academic Publishers, 41, 5-25.

Freund, Y. \& Schapire, R. E. (1999). A Short Introduction to Boosting. Journal of Japanese Society for Artificial Intelligence, 14(5), 771-780.

Kırlıoğlu, H. \& Ceylan, İ. F. (2014). Mali Tablo Denetiminde Ön Analitik İnceleme Tekniği Olarak Veri Madenciliğinin Kullanımı: Borsa İstanbul Uygulaması. Akademik Yaklaşımlar Dergisi, 5(1), 13-36.

Kıymık, H., Bekci, İ. \& Acar, D. (2015). Örgütsel Kültür ve Örgütsel Muhasebe Kültürü İle Hileli Finansal Raporlama Arasındaki İlişki: Borsa İstanbul (BIST) Hizmetler Endeksinde Bir Araştırma. Muhasebe Bilim Dünyası Dergisi, 17(4), 759-784.

Kolyiğit, Ö., Aşlıyan, R. \& Günel, K. (2012). Türkçe Dokümanlar İçin Yazar Tanıma. Uşak Üniversitesi XIV. Akademik Bilişim Konferansı Bildirileri, 423-428.

Kopun, D. (2018). A Review of the Research on Data Mining Techniques in the Detection of Fraud in Financial Statements. Journal of Accounting and Management, 8(1), 1-18.

Koskivaara, E. (2004). Artificial Neural Networks in Auditing: State Of The Art. The ICFAI Journal Of Audit Practice, 4(1), 12-33.

Kotsiantis, S., Koumanakos, E., Tzelepis, D. \& Tampakas, V. (2006). Forecasting Fraudulent Financial Statements Using Data Mining. International Journal of Computational Intelligence, 3(2), 104-110.

Liou, F. M. (2008). Fraudulent Financial Reporting Detection and Business Failure Prediction Models: A Comparison. Managerial Auditing Journal, 23(7), 650-662.

Liu, C., Chan, Y., Kazmi, S.\& Fu, H. (2015). Financial Fraud Detection Model: Based on Random Forest. International Journal of Economics and Finance, 7(7), 178-188.

Özbirecikli, M. (2013). TTK ve Hile Denetimi Süreci: Denetim Uygulamaları ve Denetçi Eğitimi Çerçevesinde Bir İnceleme. XXXII. Türkiye Muhasebe Ĕ̆itimi Sempozyumu Bildiriler Kitabı, Konya.

Rezaee, Z. (2005). Causes, Consequences and Deterence of Financial Statement Fraud. Critial Perspective on Accounting, 16, 277-298.

Sharma, T. \& Jain, M. (2013). WEKA Approach for Comparative Study of Classification Algorithm. International Journal of Advanced Research in Computer and Communication Engineering, 2(4), 1925-1931.

Söylemez, Y. \& Türkmen S. (2017). Yapay Sinir Ağları Modeli İle Finansal Başarısızlık Tahmini. Finans Ekonomi ve Sosyal Araştırmalar Dergisi, 2(4), 270-284.

Spathis, C. T. (2002). Detecting False Financial Statements Using Published Data: Some Evidence From Greece. Managerial Auditing Journal, 17(4), 179-191. 
Tatar, B., Kiymık, H. / Journal of Yasar University, 2021, 16/64, 1700-1719

SPK. Sermaye Piyasasında Bă̆ımsız Denetim Standartlarl Hakkında Teblĭg, Seri: X, No:22. https://spk.gov.tr/Sayfa/Dosya/590, (14.12.2020).

Şişmanoğlu, G., Koçer, F., Önde, M. A. \& Şahingöz, Ö. K. (2020), Derin Öğrenme Yöntemleri İle Borsada Fiyat Tahmini. BEÜ Fen Bilimleri Dergisi, 9(1), 434-445.

Terzi, S. (2012). Hileli Finansal Raporlama Önleme ve Tespit, Beta Basım Yayım AŞ. İstanbul.

Tokmak, M. \& Kıraç, A. (2021). Evrişimsel Sinir Ağları ile Örümcek Kuşugillerin Bazı Türlerinin Sinıflandırılması. Bilge International Journal of Science and Technology Research, 5(1), 72-79.

Ye, H. Xiang, L. and Gan, Y. (2019). Detecting Financial Statement Fraud Using Random Forest with Smote. IOPConference Series: Materials Science and Engineering, Number 612, 1-12. 